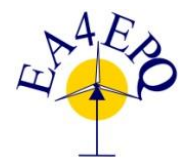

International Conference on Renewable Energies and Power Quality (ICREPQ'16)

Madrid (Spain), $4^{\text {th }}$ to $6^{\text {th }}$ May, 2016

Reneurable Energy and Pourer Quality. Fournal (RE\&PQJ)

ISSN 2172-038 X, No.14 May 2016

\title{
Vanadium Redox Flow Battery Storage System Linked to the Electric Grid
}

\author{
B.N. Arribas ${ }^{2}$, R. Melício ${ }^{1,2}$, J.G. Teixeira ${ }^{3}$ and V.M.F. Mendes ${ }^{2,4}$ \\ ${ }^{1}$ IDMEC/LAETA, Instituto Superior Técnico, Universidade de Lisboa, Lisbon, Portugal \\ ${ }^{2}$ Departamento de Física, Escola de Ciências e Tecnologia, Universidade de Évora, Portugal \\ ${ }^{3}$ HERCULES Laboratório, Departamento de Química, Escola de Ciências e Tecnologia, Universidade de Évora, Portugal \\ ${ }^{2}$ Instituto Superior de Engenharia de Lisboa, Lisbon, Portugal \\ IDMEC/LAETA, Av. Rovisco Pais, 11049-001, Lisbon, Portugal \\ Universidade de Évora, Largo dos Colegiais 2, 7000 Évora, Portugal \\ e-mail:ruimelicio@gmail.com
}

\begin{abstract}
This paper focuses on technology state of the art for the charge/discharge of electric energy storage supported by vanadium redox flow battery linked to the electric grid. Properties of vanadium, the main configuration and the reaction of charge/discharge of a vanadium redox flow battery are addressed. The vanadium redox flow battery has the highest cell voltage among the other redox flow battery, implying higher power and energy density which favours application at power plants. This electric energy storage is viewed as a promising contribution to be integrated in power system due to a reasonably bulky size and to successful applications currently allowing storage of energy at power plants or at electrical grids. For instances, allowing storage of energy as an economic improvement providing spin reserve to avoid penalty for imbalances between the energy delivered and energy contracted at closing of electricity market or as an economic improvement to diminish the cost of electricity usage of a consumer. The vanadium redox flow battery has the advantages of scalability customized to meet requirements for power and energy capacity and of excellent combination of energy efficiency, capital cost and life cycle costs compared with other technology.
\end{abstract}

\section{Key words}

Vanadium RFB, security of supply, scalability, charge/discharge, startup.

\section{Introduction}

The shortage of fossil fuels and the need for carbon footprint reduction have resulted in a global awareness of the importance of alternative energy sources, efficiency in the use of energy and a demand for sources of sustainable energy [1]. Renewable energy sources, namely wind and solar are likely to have a more significant role in the world energy supply in the upcoming years. Among the renewable energy sources, wind and solar energy has ubiquity and abundance [2]. Although, the technology of direct conversion of solar energy into electric energy has to find the way through the development of cheaper converters with satisfactory efficiency and a convenient useful life time, so, eventually solar energy is the most important source of sustainable energy for power supply, delivering electric energy in the neighbourhood of where demand is located [3]. However, due to the variable nature of the insolation, there is a need to store energy captured during periods of low usage of electric energy [4] in order to use during periods of no insolation or of higher usage [5]-[7]. Storage of energy is regarded as an economic operational practice in order to develop an action for mitigation of the cost of electricity, for instances, for consumers when electric companies apply hourly pricing [5] or for providing spinning reserve to maintain the power system frequency [8]. Nowadays, storage of energy has developments promising capability of providing a convenient performance to be an essential part of the future grid, said as smart grid [5]. For instance, in the implementation of a building integrated photovoltaic (BIPV) [9]. BIPV is expected to spread in the near future: increasing BIPV with energy storage at urban grid levels is a viable decentralized option promising a large growth potential [9].

Generally, potential energy storage technology options include compressed air storage systems, wind-hydro pump systems, flywheels, and electrochemical systems, for instances, liquid metal battery or redox flow battery (RFB). Among electrochemical systems, RFB is the one with the most recent added improvements in technology promising an opportune choice for stationary energy storage [5] and scalability [10]. The scalability is the distinctive feature of the RFB and can be customized to meet independent requirements for power and energy capacity, due to the fact that energy is not being stored in the solid electrodes but in the liquid electrolyte kept in external tanks and pumped through a reactor. The dimension of the reactor restricts the power delivered and the volume of the tanks restricts the energy stored. Due to the scalability, the RFB is referred as the best solution for power storage system [11]. The RFB has demonstrated ability to provide energy in remote areas, back-up power 
supplies, distributed power generation and power optimization [12].

The significant role of the wind power in power systems in the upcoming years implies dealing with necessary actions for helping the stability of power systems. One action to be considered in wind farms is the ability to contribute to the black-start capability of the power system, i.e., the ability to recover from a total or partial shutdown within a timeframe without any external supply [13]. Total or partial shutdown recover can be treated by black-start capability given by auxiliary services, such as a battery storage unit connected at the end of the rectifier in order to maintain system reliability and supply continuity to the capacitors banks allowing for a successful black-start [14]. Electrochemical systems are seen to be superior in comparison with the other forms of energy storage which are mainly mechanical in nature and therefore have relatively long response times compared to batteries and electrochemical capacitors. Particularly, when comparing electrochemical system performance and cost of different energy storage technology [15]. The battery industry has seen huge growth over the past few years in portable, rechargeable battery packs. The majority of this surge can be attributed to the extensive use of cell phones, personal digital assistants and other wireless electronics. Rechargeable battery systems provide direct conversion of chemical energy into electrical energy and vice versa, providing chemical energy storage to be used when the conversion into electric energy is needed. Rechargeable battery systems remained the mainstream source of power for systems ranging from mobile phones to electric and hybrid electric vehicles [16]. Lithium ion technology is currently considered as being a viable option in what regards the convenient level required for energy density and ease of operation for the application in electric and hybrid electric vehicles. While for energy storage in medium to large-scale grid connected systems the main battery technology that are attracting attention are the sodium-sulphur, lithium ion and RFB, like the ones using iron-chromium or vanadium, [15],[17]. Electrochemical energy storage is particularly pointed out as suited to be used for the storage of electrical energy in a coordination scheme with the operation plants based in renewable energy sources in order to reduce the intermittence and variability of the power available in the source [15].

The technology RFB differs from the usual rechargeable battery technology and can be understood as being a type of rechargeable fuel cell. This technology is currently receiving considerable attention due to a reasonably bulky size and to successful applications currently allowing storage of energy at power plants or at electrical grids. Benefits that make RFB a viable alternative are the long operating life time and the fact that the separation of power and energy compared with other batteries is an advantage to meet the requirements of different applications. A comparison with other energy storage technology favours RFB as offering lower capital and operating costs [15],[18]. Also, RFB can be refilled with already charged electrolyte while the original electrolyte is recharged in another RFB, speeding the refill of energy into the initial battery. The vanadium RFB has the highest cell voltage, implying higher power and an energy density which is in favour of the application for peak demand management. The technology of the vanadium RFB is one of the type of the RFB, having an acid solution where the vanadium is dissolved, usually sulphuric acid. Historically, the vanadium RFB is first mentioned in a 1933 patent by P.A. Pissoort in France. Another patent on a titanium chloride flow cell is registered by Walter Kango in Germany in 1954 [5,19]. The vanadium RFB as known today was developed at the University of New Wales by Maria Skyllas-Kazacos and co-workers [20]. A Mexican chemist Andrés Manuel del Rio in 1810 is the first to identify what is now named as vanadium. A letter intended to report to the Institute de France in Paris the method for the analysis and confirmation of what is called by Rio the new element erythronium is shipwrecked. So the letter did not arrive at the Institute de France, but a brief note arrived describing this new element as having great semblance with the already known element chromium. A Swedish chemist Nils Gabriel Sefstrôm in 1830 again identified the vanadium in samples of iron from a mine in Sweden. Lastly, an English chemist Sir Henry Enfield Roscoe in 1867 isolated vanadium. Vanadium is found in combination forms widely dispersed in the earth and is a hard, silvery grey, ductile malleable chemical element, a transition metal, with symbol V and atomic number 23.

This paper focuses on technology state of the art and the study of charge/discharge of vanadium redox flow battery linked to the electric grid. Particular, the procedure for startup and limitation are addressed. The rest of the paper is organized as follows. Section 2 summarizes the vanadium RFB technology, the charge / discharge and the procedure to startup. Finally, concluding remarks are given in Section 3.

\section{Vanadium RFB}

The vanadium RFB is an electrochemical energy storage system which converts chemical energy into electrical energy and vice versa, providing chemical energy storage to be used when the conversion into electric energy is needed. A stack of cells and the two tanks for the electrolytes of an implementation of vanadium RFB [21] are shown in Fig. 1.

Fig. 1 shows in the upper position the stacks of vanadium cells and in the lower position the two tanks for the vanadium electrolyte. The tanks are in polypropylene, the pipes and tubing are in Viton polypropylene and the ball valves are acid resistant. The vanadium is able to be in solution in four prevailing oxidation states, allowing for different behaviour as electrolytes. The Vanadium based electrolyte, manufactured by electrochemical dissolution of Vanadium Pentoxide $\left(\mathrm{V}_{2} \mathrm{O}_{5}\right)$ in mild concentrations of sulphuric acid has a virtually unlimited life and a high residual value for reuse [22]. The Vanadyl Sulphate $\left(\mathrm{VOSO}_{4}\right)$ is also Vanadium based electrolyte obtained by reduction of vanadium pentoxide with sulfur dioxide. 


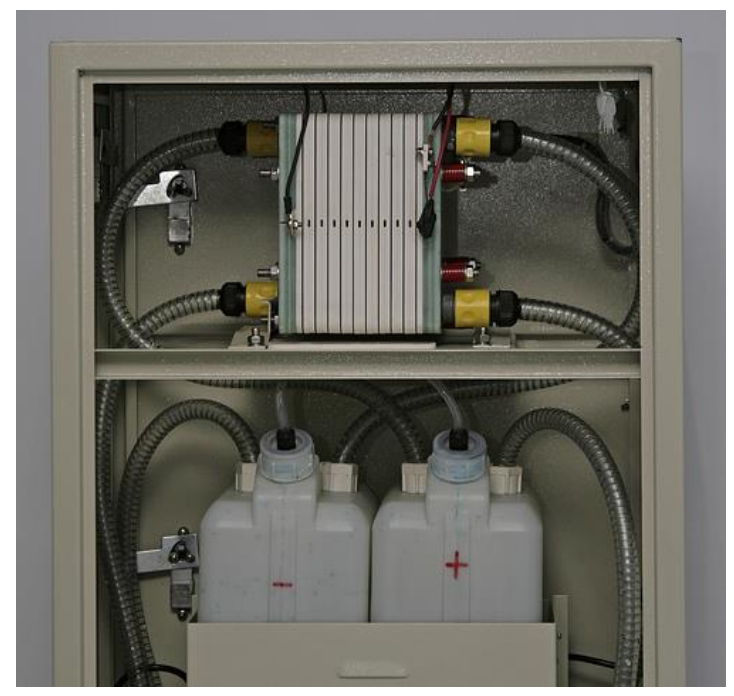

Fig. 1. Vanadium redox flow battery [21].

The colors for of the solutions for the four prevailing oxidation are [11] shown in Fig. 2.

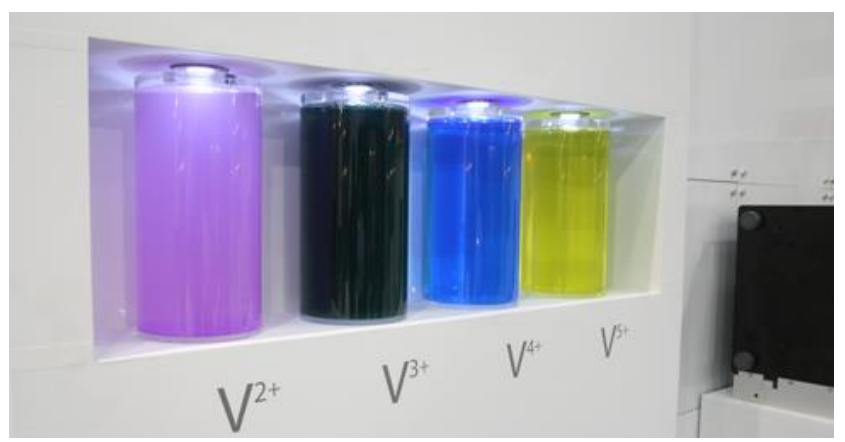

Fig. 2. Colors for the prevailing oxidation states of the dissolved vanadium [11].

Fig. 2 shows the solutions for the four prevailing oxidation states: $+2,+3,+4$ and +5 , respectively, indicated by $\mathrm{V}^{2+}, \mathrm{V}^{3+}, \mathrm{V}^{4+}$ and $\mathrm{V}^{5+}$, also referenced by $\mathrm{V}(\mathrm{II}), \mathrm{V}(\mathrm{III}), \mathrm{VO}^{2+}$ and $\mathrm{VO}_{2}^{+}$with colour violet, bluegreen, blue and yellow to the respective solutions.

The energy converting system is the cell stack electrically connected using association of cells in series or in parallel, or both. A vanadium RFB cell stack [21] is shown in Fig. 3.

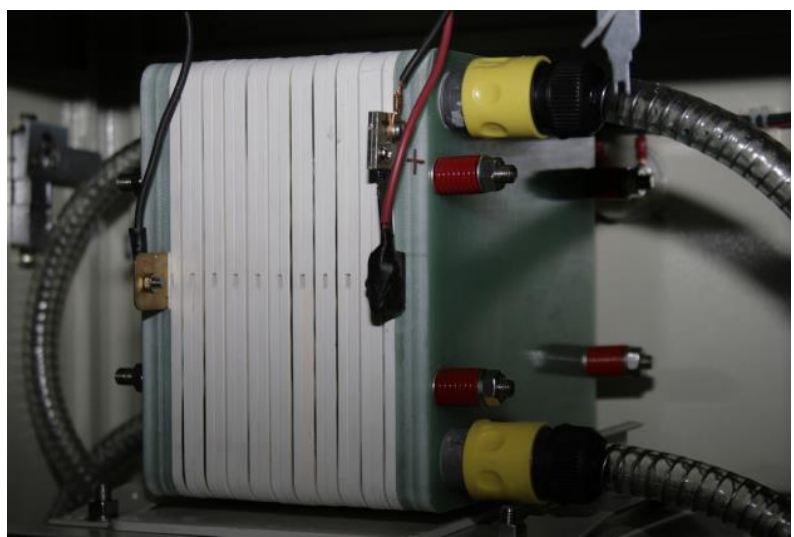

Fig. 3. Vanadium redox flow battery stack [21].
Fig. 3 shows the cell stack negative and positive electric terminal at the left and right, respectively. The electrolyte is forced into the stack by pumping. The volume of the electrolyte of vanadium RFB determines the capacity of the battery depending upon the vanadium concentration [18]. The size of the electrodes and the number of cells in the stack determines the power of the battery [23]. The concentration of vanadium in the electrolyte increases the energy density in the battery, but any increases in vanadium ion concentration above $2 \mathrm{M}$ in the sulfuric acid supporting electrolyte, leads to supersaturation of the solutions resulting in the precipitation of the electrolyte at low temperatures in the case of $\mathrm{V}$ (II)/ $\mathrm{V}$ (III) or $\mathrm{V}$ (IV) solutions, or at high temperatures in the case of $\mathrm{V}(\mathrm{V})$ solution. So, vanadium solutions of concentration greater than $2 \mathrm{M}$ need further achievements in order to be employed in the first generation of vanadium RFB [18]. Efforts are being made to improve the stability of $3 \mathrm{M}-$ $4 \mathrm{M}$ supersaturated vanadium solutions in sulfuric acid [18]. The structure of a cell of vanadium RFB [22] is shown in Fig. 4.

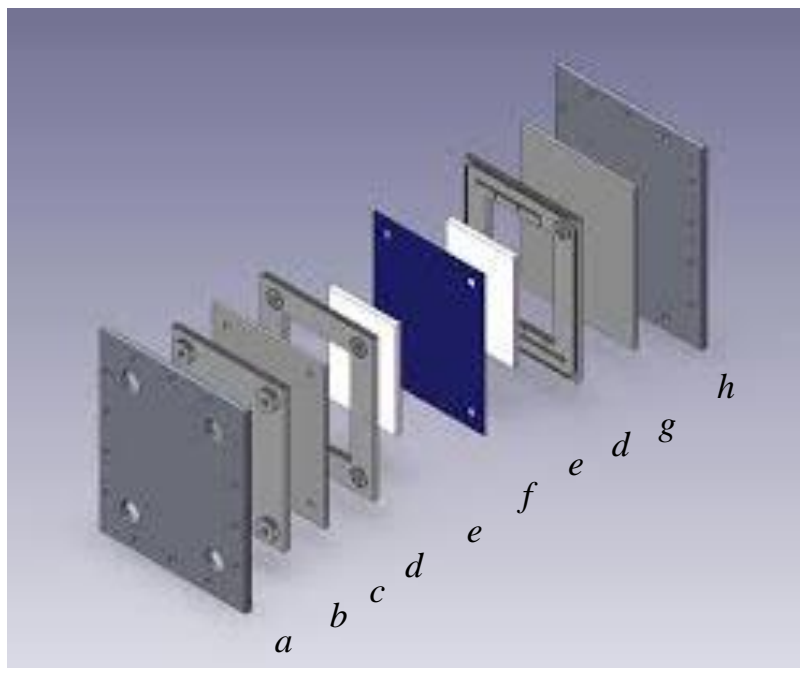

Fig. 4. Schematic diagram of the vanadium redox flow battery cell [22].

Fig. 4 shows a cell structure where: $a$ is the steel plate, $b$ is the isolation plate, $\mathrm{c}$ is the flow-through graphite electrode, $\mathrm{d}$ is the flow frame, $\mathrm{e}$ is the graphite felt, $\mathrm{f}$ is the proton exchange membrane, $\mathrm{g}$ is the graphite electrode, $h$ is the steel plate. The proton exchange membrane separates the cell in two half-cells. The Selemion or the Nafion are used as proton exchange membrane [15]. The levelized cost of energy of a vanadium $\mathrm{RBF}$ is already less than half the cost of other battery technology. Low maintenance, lifetime in other of two decades or ten thousands of charging cycles and efficiency in order of eighty percent with a one hundred percent of depth of discharge are point out as significant for convenient option to assist in the integration of renewable energy in electric grids.

A direct current circuit battery management system, DC Circuit BMS, which is an integrated complementary electric circuit, is needed to allow for: monitoring the state, processing and reporting secondary data, protecting 
and controlling the environment of the vanadium redox flow battery. The monitoring of the state allows for accessing critical information, such as: total voltage at the terminal or voltages of individual cells; electric current at the terminal; average cells temperature or temperatures of individual cells; level of charge or depth of discharge; state of health, a measurement of the overall condition of the vanadium redox flow battery, for instances, internal impedance, capacity, self-discharge, ability to accept a charge. A schematic of a hybrid photovoltaic wind power system connected to the electrical grid and having energy storage by vanadium RFB is shown in Fig. 5.

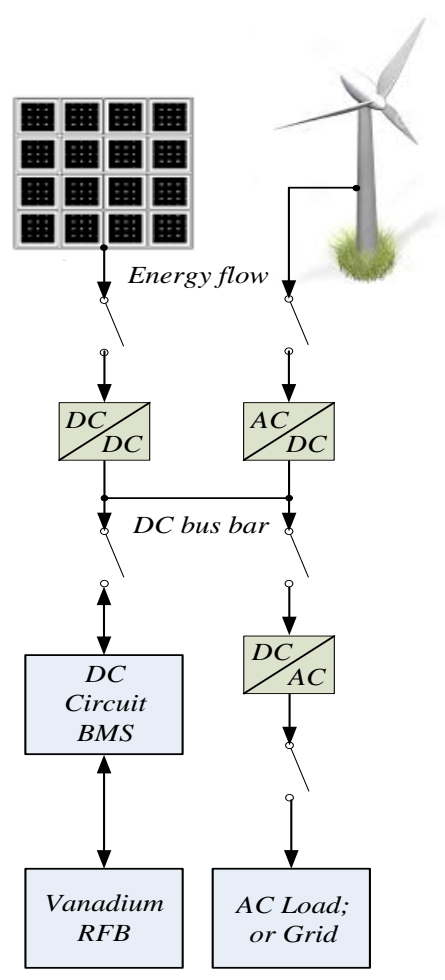

Fig. 5. Vanadium redox flow battery connected to the grid.

Fig. 5 shows the DC/DC, AC/DC and DC/AC, respectively, the electric power converts of direct current into direct current known as the boost converter, the alternate current into direct current and vice versa converters.

The boost converter is needed to increment the voltage to the appropriated level of the voltage at the DC bus bar. The AC/DC converter is needed to convert the alternate current which is not necessarily at a constant frequency into the direct current having a voltage of the DC bus bar. The DC/AC converter is needed to convert the direct current into alternate current at a constant frequency to be connected to the grid.

The cell open circuit voltage $V_{O C}$ can be defined by the Nernst law [26], dealing not only with the cell potential, but also with the energy of the chemical reaction. The energy of the chemical reaction forces the charges to go into movement. This cause of movement furnishes the cell potential. The Nernst law is stated by the equation given by

$V_{O C}=E_{0}+\frac{R T}{n F} \ln \left(\frac{C_{V O_{2}^{+}}}{C_{V O^{2+}}} C_{H^{+}}^{2} \frac{C_{V^{2+}}}{C_{V^{3+}}}\right)$

In (1), $E^{0}$ is the value for the standard cell potential, $R$ is the ideal gas constant $8.314 \mathrm{~J} \mathrm{~mol}^{-1} \mathrm{~K}^{-1}, F$ is the Faraday constant $9684.56 \mathrm{C} \mathrm{mol}^{-1}, n$ is the number of moles of electrons transferred in the balance equation, $T$ is the absolute temperature, $C_{i}$ is the concentration of the species $i$. The Nernst equation relates the reduction potential of a half-cell at any point in time to the standard electrode potential, temperature, activity, and reaction quotient and species used [26].

A more detail including the electrochemical reactions of the vanadium RFB diagram of the vanadium redox flow battery and the charge discharge processes, coupled to an integrated complementary electric circuit linked to the DC bus bar is shown in Fig. 6. Fig. 6 shows in the halfcells the identification of the electrochemical reactions taking place on the electrodes, an inert carbon felt polymer composite, from which an external DC current circulates at the terminals to charge and discharge the vanadium RFB [24]. The electrolytic solutions are circulated from the reservoirs to the stack using two pumps in order to enable the main electrochemical reaction at the cells inert electrodes [25] and renew the amount of the oxidant ions $\left(\mathrm{VO}_{2}{ }^{+}\right)$and reducing ions $\left(\mathrm{V}^{2+}\right)$ at the respective electrode's surface. The discharge of the battery imposes that in the negative half-cell of the stack, V(II) ions in solution are converted to V(III) ions with the loss of an electron, which is available for electric conduction in the process [26]. The reaction is given by

$V^{2+} \underset{\text { charge }}{\stackrel{\text { disch } \arg e}{\longrightarrow}} V^{3+}+e^{-}, E^{0}=-0.255 \mathrm{~V}$

The discharge imposes that in the positive half-cell of the stack, $\mathrm{V}(\mathrm{V})$ ions $\left(\mathrm{VO}_{2}^{+}\right)$are converted to $\mathrm{V}(\mathrm{IV})$ ions $\left(\mathrm{VO}^{2+}\right)$ with the gaining of one electron in the process [26]. The reaction is given by

$\mathrm{VO}_{2}^{+}+e^{-}+2 \mathrm{H}^{+} \underset{\text { charge }}{\stackrel{\text { disch } \arg e}{\longleftarrow}} \mathrm{VO}^{2+}+\mathrm{H}_{2} \mathrm{O}$
$E^{0}=1.0 \mathrm{~V}$

where the water $\left(\mathrm{H}_{2} \mathrm{O}\right)$ and the protons $\left(\mathrm{H}^{+}\right)$are required in the cathodic reaction to maintain the charge balance and the stoichiometry [20]. The vanadium RFB stack shown in Fig. 6 illustrates that, for both charge and discharge states, two simultaneous reactions occur on both sides of the membrane. During the discharge the reduction take place in the cathode and the oxidation in the anode, hence electrons are removed from the anode and transferred through the external circuit to the cathode. 


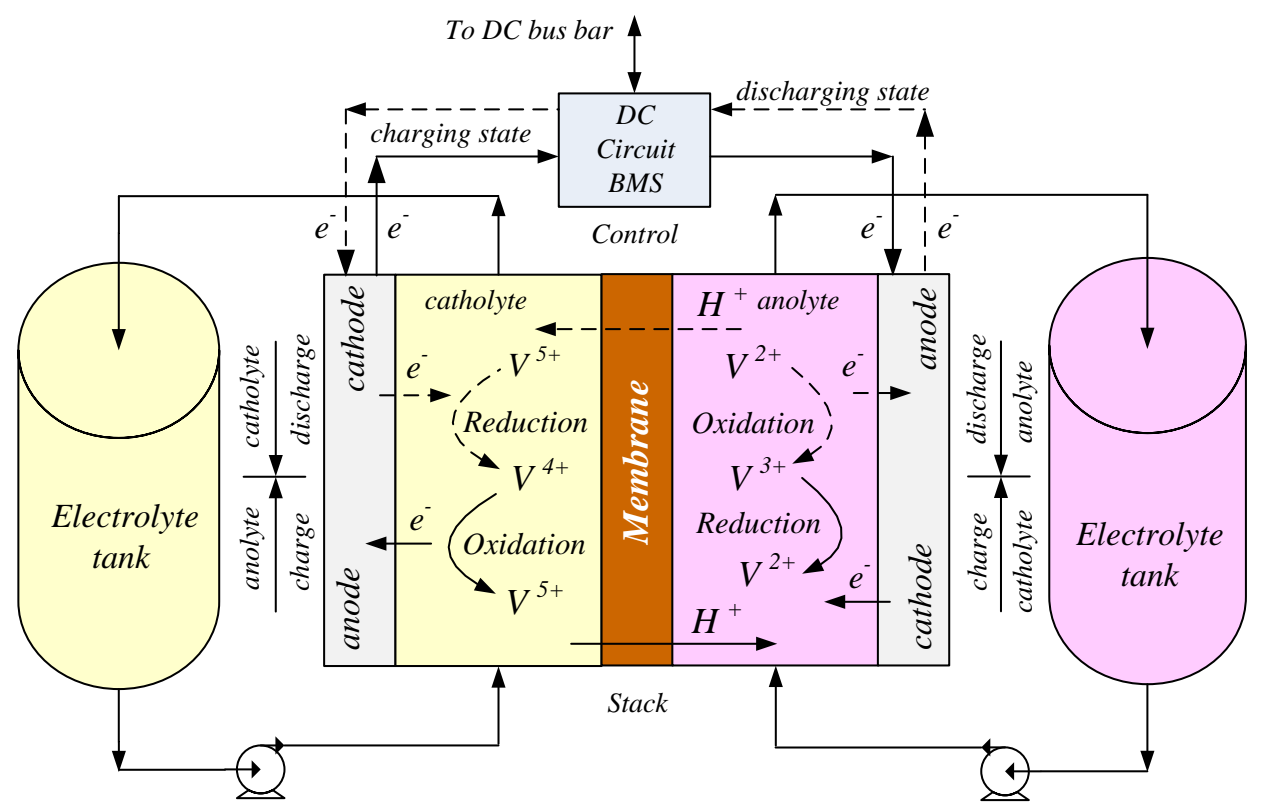

Fig. 6. Vanadium RFB reaction, charge / discharge linked to the DC bus bar.

During the charge, the electrochemical reactions in each electrode are driven (externally) in the opposite direction; now, the reduction takes place in the electrode that worked in the discharge as anode, while the oxidation takes place in the electrode that worked as a cathode. Briefly, in the discharge of the vanadium RFB and in its charging, the polarity of the electrodes is the same, while their designations and electrode reactions are reversed. Meanwhile, whatever the running conditions of vanadium RFB, the protons $\left(H^{+}\right)$diffuses from the anolyte to the catholyte.

The procedure to startup [8] is the following:

- The electrolyte preparation is based on the electrolysis of the vanadyl sulphate $\mathrm{VOSO}_{4}$ to obtain the $\mathrm{VO}^{2+}$ given by

$\mathrm{VOSO}_{4} \rightarrow \mathrm{VO}^{2+}+\mathrm{SO}_{4}^{2-}$

- The electrolysis reaction occurs in an electrolytic cell, inert gas is used to blanket the electrolyte to minimize the contact with the oxygen present in the atmosphere to prevent the oxidation of the $V^{2+}$ solution [27]. Hence, the primary catholyte is obtained from an electrolytic oxidation of the $\mathrm{VOSO}_{4}$ solution given by

$\mathrm{VO}^{2+}+\mathrm{H}_{2} \mathrm{O} \rightarrow \mathrm{VO}_{2}^{+}+2 \mathrm{H}^{+}+e^{-}$.

- The primary anolyte is obtained from an electrolytic reduction given by

$\mathrm{VO}^{2+}+2 e^{-}+2 \mathrm{H}^{+} \rightarrow \mathrm{V}^{2+}+\mathrm{H}_{2} \mathrm{O}$.

- The filling of storage tanks ensure that the battery is ready to starts charging. When the reference cell voltage reaches over $1.6 \mathrm{~V}$, the charge is completed [27].

- The startup time of the battery is limited by the time required to flow enough active species into the stack to sustain the electrochemical reaction rate and not by the reaction itself [27]

\section{Conclusion}

Exploitation of sources of renewable energy having power fluctuation in other to integrate into electric grids demands for the practice of storing energy to assist in dealing with power smoothing on the fluctuation. Redox flow batteries exhibit many technical benefits over other energy storage systems and combine excellent energy efficiency with capital and operating costs comparatively low towards other energy storage technology, which surpass the constraints associated with their limited volumetric energy densities and complex system design. The vanadium RFB, in particular, whose main limitations are dictated by the solubility of vanadium ions and their mass-transport rates in the flowing electrolyte solutions, are in forefront of large-scale energy storage technologies because they exhibit: a high nominal cell voltage, a long cycle life, an excellent shelf life, a high chemical compatibility between the two electrolyte solutions with low sensitivity to their mutual contamination or accidental mixing, and a competitive cost as well as reduced operation and maintenance costs. As the volume of the tank increases, the price per unit of energy stored decreases. In addition, if absolutely necessary, the vanadium RFB has the capacity to be recharged through non-electric means (replacing the solutions of the reservoirs, with the oxidant and reductant at maximum concentrations). 


\section{Acknowledgments}

This work is funded by Portuguese Foundation for Science \& Technology, through IDMEC, under LAETA, project UID/EMS/50022/2013.

\section{References}

[1] L. Schaefer, "Editorial", Sustainable Energy Technologies and Assessments, vol. 1, pp. 1-2, March 2013.

[2] B. Bouzidi, "New sizing method of PV water pumping systems", Sustainable Energy Technologies and Assessments, vol. 4, pp. 1-10, December 2013.

[3] M.C. Di Piazza, M. Pucci, and G. Vitale, "New sizing method of PV water pumping systems", Sustainable Energy Technologies and Assessments, vol. 2, pp. 19-30, June 2013.

[4] R.P. Brooker, C.J. Bell, L.J. Bonville, and H.R. Kunz, "Determining vanadium concentrations using the UV-Vis response method", Journal of the Electrochemical Society, vol. 162, pp. A608-A613, 2015.

[5] P. Alloto, M. Guarnieri, and F. Moro, "Redox flow batteries for the storage of renewable energy: a review", Renewable and Sustainable Energy Reviews, vol. 29, pp. 325-335, 2014.

[6] I. González, M. Ramiro, A.J. Calderón, and J.F. González, "Estimation of the state-of-charge of gel lead-acid batteries and application to the control of a stand-alone wind-solar test-bed with hydrogen support", International Journal of Hydrogen Energy, vol. 37, pp. 11090-11103, 2012.

[7] B. Turker, S.A. Klain, L. Komsiyska, J.J. Trujillo, L. von Bremen, M. Kühn, and M. Busse, "Utilizing a vanadium redox flow battery to avoid wind power deviation penalties in an electricity market", Energy Conversion and Management, vol. 76, pp. 1150-1157, 2013.

[8] C. Blanc, "Modeling of a vanadium redox flow battery electricity storage system". $\mathrm{PhD}$ Thesis, École Polytechnique Fédérale de Lausanne, Switzerland, 2009.

[9] H.P. Ikkurti, and S. Saha, "A comprehensive technoeconomic review of microinverters for building integrated photovoltaic (BIPV)", Renewable and Sustainable Energy Review, vol. 47, pp. 997-1006, 2015.

[10] PV Tech Storage, http://storage.pvtech.org/interviews/american-vanadium-mining-forbillions-in-the-nevada-desert, 2015.

[11] $\mathrm{H} 2$ <http://www.h2aec.com/english/product/vrfb.asp>, 201

[12] G. Kear, A.A. Shah, and F.C. Walsh, "Development of the all-vanadium redox flow battery for energy storage: a review of technological, financial and policy aspects", International Journal of Energy Research, vol. 36, pp. 1105-1120, 2012.
[13] E. Belenguer, R. Vidal, R. Blasco-Giménez, H. Beltran, J.C. Alfonso, and C. Ariño, "Islanded operation and control of offshore wind farms connected through a VSCHVDC link", in: International Conference on Renewable Energies and Power Quality, 1-6, Bilbao, Spain, March 2013.

[14] M. Aktarujjaman, M.A. Kashem, M. Negnevitsky, and G. Ledwich, "Black start with DEIG based distributed generation after major emergencies", in: IEEE International Conference on Power Electronics, Drives and Energy Systems, 1-6, New Delhi, India, March 2006.

[15] M. Skyllas-Kazacos, M.H. Chakrabarti, S.A. Hajimolana, F.S. Mjalli, and M. Saleem, "Progress in flow battery research and development", Journal of The Electrochemical Society, vol. 158, pp. R55-R79, 2011.

[16] P. Arora, and Z. Zhang, "Battery separators", Chemical Review, vol. 104, pp. 4419-4462, 2004

[17] S. Corcuera, and M. Skyllas-Kazacos, "State-of-charge monitoring and electrolyte rebalancing methods for the vanadium redox flow battery", European Chemical Bulletin, vol. 1, pp. 511-519, 2012.

[18] F. Rahman, and M. Skyllas-Kazacos, "Vanadium redox battery: positive half-cell electrolyte studies", Journal of Power Sources, vol. 189, pp. 1212-1219, 2009.

[19] M. Bartolozzi, "Development of redox flow batteries. A historical bibliography", Journal of Power Sources, vol. 27, pp. 219-234, 1989.

[20] E. Sum, and M. Skyllas-Kazacos, "A study of the $\mathrm{V}(\mathrm{II}) / \mathrm{V}(\mathrm{III})$ redox couple for redox flow cell applications", Journal of Power Sources, vol. 15, pp. 179190, 1985.

[21] Flickr,

<https://www.flickr.com/photos/energylabdcu/sets/72157 622243017037/>, 2015

[22] J. Noack, and J. Tübke, "Redox flow energy storage for fluctuating renewable energies", in: International Stationary Battery Conference, 1-10, Pompano Beach, USA, March 2009.

[23] Z. Yang, J. Zhang, M.C.W. Kintner-Meyer, X. Lu, D. Choi, P.J. Lemmon, and J. Liu, "Electrochemical energy storage for green grid", Chemical Reviews, vol. 111, pp. 3577-35613, 2011.

[24] L.J. Ontiveros, and P.E. Mercado, "Modeling of a vanadium redox flow battery for power dynamic studies", Journal of Hydrogen Energy, vol. 39, pp. 8720-8727, 2014

[25] G. Merei, S. Adler, D. Magnor, M. Leothold, and D.U. Sahuer, "Multi-physics model for a vanadium redox flow battery", Energy Procedia, vol. 46, pp. 194-203, 2014.

[26] F. Baccino, M. Marinelli, P. Nøgård, and F. Silvestro, "Experimental testing procedures and dynamic model validation for vanadium redox flow battery storage system", Journal of Power Sources, vol. 254, pp. 277-286, 2014.

[27] C. Blanc, and A. Rufer, "Understanding the vanadium redox flow batteries", in: Paths to Sustainable Energy, InTech, Rijeka, Croatia, pp. 333-358, 2010. 